Produto \& Produção, vol. 10, n. 2, p. 62 - 86, jun. 2009

\title{
$\mathbf{P} P$
}

\section{Múltiplo Estudo de Casos sobre a Inserção do QFD no Processo de Desenvolvimento de Novos Produtos}

\author{
Ivan Antônio Formággio \\ Programa de Pós-Graduação em Engenharia de Produção, UNIMEP \\ formaggio@dglnet.com.br \\ Paulo A. Cauchick Miguel , PhD \\ Departamento de Engenharia de Produção, Escola Politécnica, USP \\ cauchick@usp.br
}

\begin{abstract}
RESUMO
$\mathrm{Na}$ busca das melhores práticas de desenvolvimento de produto, novas abordagens têm sido aplicadas para desenvolver novos produtos. Entre as práticas utilizadas pelas empresas estão os processos estruturados de desenvolvimento. Entretanto, estas estruturas exigem que outros métodos venham a completá-los, como no caso do QFD (Desdobramento da Função Qualidade), que tem por objetivo incorporar as exigências dos clientes nas especificações do produto. Nesse sentido, o objetivo desse artigo é apresentar múltiplos estudos de caso sobre como as empresas consideram o QFD em seus processos de desenvolvimento de produto. Foram estudadas cinco empresas que utilizam o QFD em seu processo de desenvolvimento de produto. Os dados e informações foram obtidos por meio de entrevistas semi-estruturadas e fontes documentais das respectivas empresas. O trabalho apresenta os resultados em cada empresa investigada e conclui que a inserção do QFD no processo de desenvolvimento de produtos depende da definição estratégica associada ao uso do método.
\end{abstract}

Palavras-Chave: Desenvolvimento de Produto. Desdobramento da Função Qualidade. QFD. 


\section{INTRODUÇÃO}

Pesquisas indicam que grande parte dos produtos lançados no mercado dos países industrializados fracassaram (DIMANCESCU; DWENGER, 1997). Na realidade, de cada 100 idéias de novos produtos somente quatro obtiveram o sucesso esperado (GRIFFIN, 1997). Assim, visando reduzir essas limitações e na busca da melhoria das práticas de desenvolvimento de novos produtos, processos organizacionais estruturados têm sido desenvolvidos por instituições de pesquisa e por empresas para desenvolver novos produtos (GRIFFIN, 1997). Dentre esses processos, está o stage gate system, desenvolvido por Cooper (1993) e utilizados por várias empresas tais como Bombardier, Kodak, Motorola, dentre outras (PHILLIPS et al, 1999). Esses processos estruturados permitem às empresas maior segurança, controle e rapidez nas atividades que são exigidas durante o processo de desenvolvimento de produto, buscando disponibilizar no momento certo, o melhor produto, tendo em vista as necessidades dos clientes e os objetivos de ganhos da empresa.

No entanto, esses modelos exigem que outros métodos e ferramentas venham a complementá-los, de forma que auxiliem eficientemente na conduta de cada uma das atividades que fazem parte do ciclo de desenvolvimento de novos produtos. Um dos métodos que as empresas têm buscado implantar para dar suporte ao desenvolvimento de novos produtos é o QFD (Quality Function Deployment ou Desdobramento da Função Qualidade). O método tem por objetivo integrar as necessidades dos clientes em todo o ciclo de desenvolvimento de um novo produto. O QFD converte as exigências dos usuários em características da qualidade (especificações) e as transfere para as etapas subseqüentes de desenvolvimento de produto, por meio de desdobramentos sucessivos.

Devido a importância da existência de um processo estruturado para desenvolver novos produtos e também da adoção do QFD, o objetivo desse artigo é compreender melhor, por meio da realização de cinco estudos de caso, como o método tem sido inserido ao longo desse processo. Mais especificamente, o trabalho pretende identificar em quais estágios do processo de desenvolvimento o QFD é utilizado, a intensidade com que o método é aplicado ao longo desse processo, considerando o número de matrizes do QFD desenvolvidas e como são distribuídas ao longo do processo de desenvolvimento (em quais estágios) e verificar se as empresas têm adotado todos os desdobramentos (qualidade, tecnologia, custos e confiabilidade). Também pretende-se verificar se o QFD amplo (formado pelo QD - desdobramento da qualidade e pelo QFDr desdobramento da função qualidade no sentido restrito) está sendo utilizado. Finalmente, pretende-se também fazer uma avaliação preliminar de quanto o nível de conhecimento sobre o QFD influencia em sua aplicação no processo de desenvolvimento.

Assim, investigando-se esses aspectos, por meio da realização dos estudos de caso, será possível verificar se as empresas têm utilizado o QFD parcialmente, em algum momento do processo de desenvolvimento ou integralmente, como um método para robustecer este processo, propiciando maior rapidez e segurança no desenvolvimento de produtos. 
Segundo Griffin (1997) e Cooper et al. (2002), mais da metade das empresas pesquisadas pelos autores, utilizam algum tipo de modelo estruturado para o desenvolvimento de novos produtos. No Brasil, empresas como a Eaton (VALERI et al., 2000) e a Natura (NASCIMENTO \& MARX, 2001), por exemplo, já utilizam modelos similares como forma de estruturar o processo de desenvolvimento de seus produtos.

Embora a literatura apresente uma série de processos de desenvolvimento de novos produtos (e.g. CLARK e WHEELWRIGHT, 1993; GRIFFIN e PAGE, 1993; 1996; RAHMAN, 1995; GUNASEKARAN, 1998; PETER et al., 1999; PHILLIPS, 1999; ROZENFELD et al., 2006), um dos processos extensivamente utilizado é o stage-gate, proposto por Cooper (1993). As melhores práticas para desenvolvimento de novos produtos são geralmente apoiadas na implementação desse tipo de processo (GRIFFIN, 1997). Nesse contexto, apresenta-se a seguir uma descrição desse processo de desenvolvimento de novos produtos, bem como apresenta-se, na seqüência, uma síntese sobre o método QFD, visando estabelecer a base teórica para a investigação empírica por meio dos estudo de casos.

\subsection{Desenvolvimento de Produto através do Staqe Gate System}

O processo de desenvolvimento denominado stage-gate system possui estágios que guiam o desenvolvimento de um produto, desde a idealização, até seu lançamento no mercado (COOPER, 2003). Uma característica deste tipo de processo é que cada estágio é bem definido e entre cada um dos estágios existe uma revisão periódica, denominada de gate, que avalia o cumprimento das atividades e tarefas de cada estágio do processo de desenvolvimento. Se o estágio avaliado estiver completo o projeto é aprovado ed passa para o estágio seguinte. Caso contrário, o estágio deve ser novamente realizado para corrigir as imperfeições. A Figura 1 ilustra a seqüência dos estágios do stage-gate, evidenciando também a presença de cada ponto de revisão periódico (gate). Cada um desses estágios é resumido na seqüência da figura.

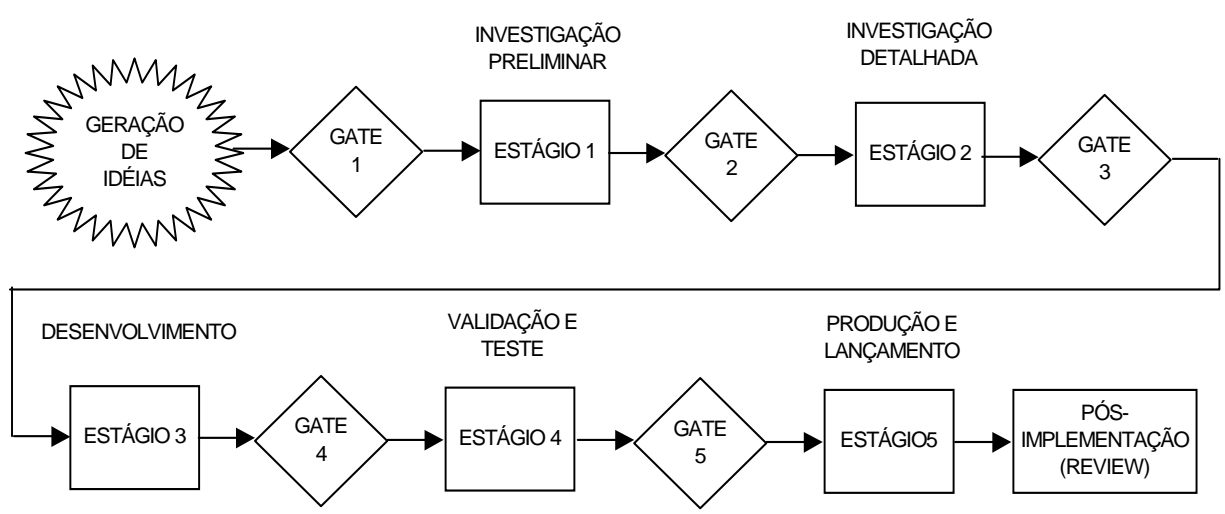

Figura 1 - Estrutura do Stage Gate System (COOPER, 1993). 


\subsubsection{Geração de Idéias}

As possíveis idéias relacionadas a novos produtos que podem vir de várias fontes, podendo ser internas e externas. As fontes internas são aquelas cujas idéias são geradas dentro da própria companhia, de todos os possíveis setores. As fontes externas são aquelas que estão ligadas indiretamente à empresa, tais como clientes, universidades, fornecedores, consultores, etc. (COOPER, 1993). Uma das técnicas utilizadas para a geração de idéias é o brainstorming, que pode ser descrito como um método para gerar idéias através de grupos de pessoas, que opinam através de suas experiências profissionais vivenciadas, formas de estimular o desenvolvimento de novos produtos (PAHL \& BEITZ, 1993). Outras práticas também podem ser adotadas como por exemplo o pensamento lateral e os desenvolvimentos por analogia. A partir de uma idéia potencial, esta necessita ser melhor desenvolvida, por meio de uma análise técnica e/ou econômica; isso é feito por uma investigação preliminar.

\subsubsection{Investigação Preliminar - Estágio 1}

Quando a empresa possuir algumas idéias potenciais, a tarefa a seguir será separá-las, selecioná-las de acordo com sua importância e verificar se realmente essa idéia deve ser conduzida para o desenvolvimento de um projeto de novo produto. No estágio 1, a empresa destina uma quantidade limitada de tempo e recursos para obter dados e informações iniciais necessárias para que o projeto possa ser completado no estágio seguinte. Apesar das despesas financeiras nesse estágio serem relativamente mais baixas, o estágio 1 é o primeiro estágio onde recursos são formalmente alocados para o desenvolvimento de um novo produto. Este estágio por ser o início de todo o processo de desenvolvimento do produto, e todos os outros estágios subsequentes estarão ligados a ele. Assim, deve ser conduzido com bastante critério. A investigação preliminar pode ainda ser subdividida em avaliação preliminar de mercado, avaliação técnica preliminar e avaliação financeira preliminar (COOPER, 1993). Algum nível de planejamento de projeto (escopo, prazo, custos, etc.) também deve ser considerado, analisando então o projeto não somente sob o ponto de vista técnico mas também financeiro e de planejamento e exequibilidade.

\subsubsection{Investigação Detalhada - Estágio 2}

Neste estágio, as avaliações preliminares iniciadas no estágio anterior, devem ser complementadas. Este é geralmente o mais difícil e o mais dispendioso dos estágios de pré-desenvolvimento (COOPER, 1993). O estágio 2 pode ser sub-dividido nas seguintes fases: análise financeira, análise de mercado, necessidades de mercado, análise competitiva, avaliação técnica detalhada, e projeto conceitual. Para cada uma 
destas fases existem vários métodos e ferramentas que podem ser empregados, como por exemplo, análise descritiva, análise fatorial, análise de correspondência (POLIGNANO \& DRUMOND, 2001) e também o QFD (COOPER, 1993; CHENG et al., 1995; AKAO, 1996). O QFD pode ser utilizado para o levantamento de informações técnicas para conceituar produtos (SARANTOPOULOS et al., 1999), possibilitando transformar as informações de mercado em parâmetros técnicos de produto. Ao final desse estágio deve ser criado um projeto conceitual que possibilite verificar se as necessidades dos clientes foram totalmente compreendidas e incorporadas. Para BAXTER (2000), um projeto conceitual deve demonstrar como os produtos deverão atender as necessidades dos clientes, como serão diferenciados dos concorrentes, e quais seus princípios funcionais.

\subsubsection{Desenvolvimento - Estágio 3}

No estágio 3 inicia-se o desenvolvimento propriamente dito, conforme destacado por Cooper (1993). Nesse estágio é traduzido o plano de negócios para algo físico e possível de ser entregue. Deve ser lembrado que ao final do presente estágio deve resultar em um protótipo de produto validado via testes laboratoriais e também com clientes. Esse protótipo é a representação física do produto final, que será produzido em escala industrial, inclusive passando por todos os testes de funcionamento. Segundo BAXTER (2000), este pode ser classificado em protótipo de pré-produção (tamanho, forma e função) e protótipo para a produção (materiais e processos prontos para a produção).

\subsubsection{Validação e Teste - Estágio 4}

O propósito do estágio 4 é proporcionar uma validação total para o projeto sob o âmbito comercial, ou seja, relacionado à produção e comercialização do produto, homologando o processo e certificando o produto. As atividades típicas devem incluir extensos testes do produto na fábrica, testes em campo com clientes ou usuários, testes de mercado e produção piloto.

\subsubsection{Lançamento no Mercado - Estágio 5}

A avaliação final da decisão de seguir para o lançamento e produção final depende dos resultados encontrados nos testes de mercado e amostras da produção piloto. Neste estágio, a empresa deve estimar os custos de produção e marketing, volumes de vendas, preço final e a margem de lucro esperada. Antes que o produto seja movido para uma escala comercial, uma minuciosa análise financeira deve ser realizada, de forma a definir um valor mínimo percentual de retorno que o produto pode trazer. 


\subsection{Desdobramento da Função Qualidade - QFD}

OHFUJl et al. (1997) definem o QFD como Desdobramento da Função Qualidade no sentido amplo (QFD), sendo constituído pelo Desdobramento da Qualidade (QD) e Desdobramento da Função Qualidade no sentido restrito (QFDr).

O QD é definido como: conversor das exigências dos usuários em características da qualidade; definição da qualidade do projeto do produto acabado; desdobramento da qualidade em qualidade de outros itens. Para CHENG et al. (1995), no QD são definidos as metas do produto e os desdobramentos sucessivos. As metas do produto estão relacionadas com a própria estratégia da empresa em relação a possibilidade de disponibilizar o produto no mercado. Nos desdobramentos sucessivos são utilizados tabelas, matrizes e modelos conceituais, para que as informações dos clientes possam ser transformadas em características técnicas de produtos através das etapas de desenvolvimento.

A primeira matriz do QFD, que é a matriz da qualidade, é formada pela união da "tabela de desdobramento da qualidade exigida" com a "tabela de desdobramento das características da qualidade" (AKAO, 1996). Nessa matriz são realizadas relações de três tipos (CHENG et al., 1995): extração (qualitativa), conversão (quantitativa) e de correlação (intensidade). A extração acontece quando os elementos de uma tabela são obtidos a partir de outra; a correlação consiste em identificar o grau de influência (forte, média, fraca e inexistente) que um item de uma tabela exerce sobre outra; e a conversão consiste em transferir a importância, ou seja, o peso relativo a cada item de uma tabela para os itens de outra tabela, através das correlações identificadas no interior da matriz.

Para finalizar, na matriz da qualidade são estabelecidas a qualidade planejada e a qualidade projetada. Segundo AKAO (1996), existem dois pontos de vista para determinar a qualidade planejada: um é o ponto de vista do cliente, ou seja, quais são as qualidades mais importantes para ele, e o segundo é o da própria empresa, que compara ela própria com os concorrentes. A qualidade projetada deve ser considerada como o plano de melhoria para as características da qualidade do produto. Segundo CHENG et al. (1995), o plano de melhoria significa definir novos valores para as características da qualidade ou manter os valores atuais, com o objetivo de superar os concorrentes naqueles itens de maior importância segundo o mercado.

A partir da qualidade projetada para o produto, a próxima fase do desenvolvimento é projeto do produto e do processo, ou seja, é o estabelecimento de outras matrizes para se atingir o objetivo geral do QFD. Estas outras matrizes podem ser, além do desdobramento da qualidade, o desdobramento da tecnologia, desdobramento de custos e desdobramento da confiabilidade. Este seqüenciamento forma o modelo conceitual. Este modelo representa o conjunto de tabelas e matrizes seqüenciadas que permitem dar visibilidade das relações existentes entre todos os componentes do processo de desenvolvimento (processos, matérias-primas, etc.), com a qualidade projetada para o produto (CHENG et al., 1995). A Figura 2 ilustra as unidades básicas de trabalho para o QD.

Assim, o conjunto das tabelas, matrizes e desdobramentos sucessivos forma 0

QD. Entretanto, é necessário o QFDr para resultar no QFD no sentido amplo. Para 
CHENG et al. (1995), o QFDr é um processo sistemático de desdobramento do trabalho da ação gerencial de planejamento da qualidade em procedimentos gerenciais e técnicos para serem cumpridos pelas áreas funcionais da empresa. O desdobramento do trabalho se divide em dois importantes documentos descritivos: um é o Padrão Gerencial do Desenvolvimento de Produtos e o outro é o Plano de Atividades do Desenvolvimento do Produto.

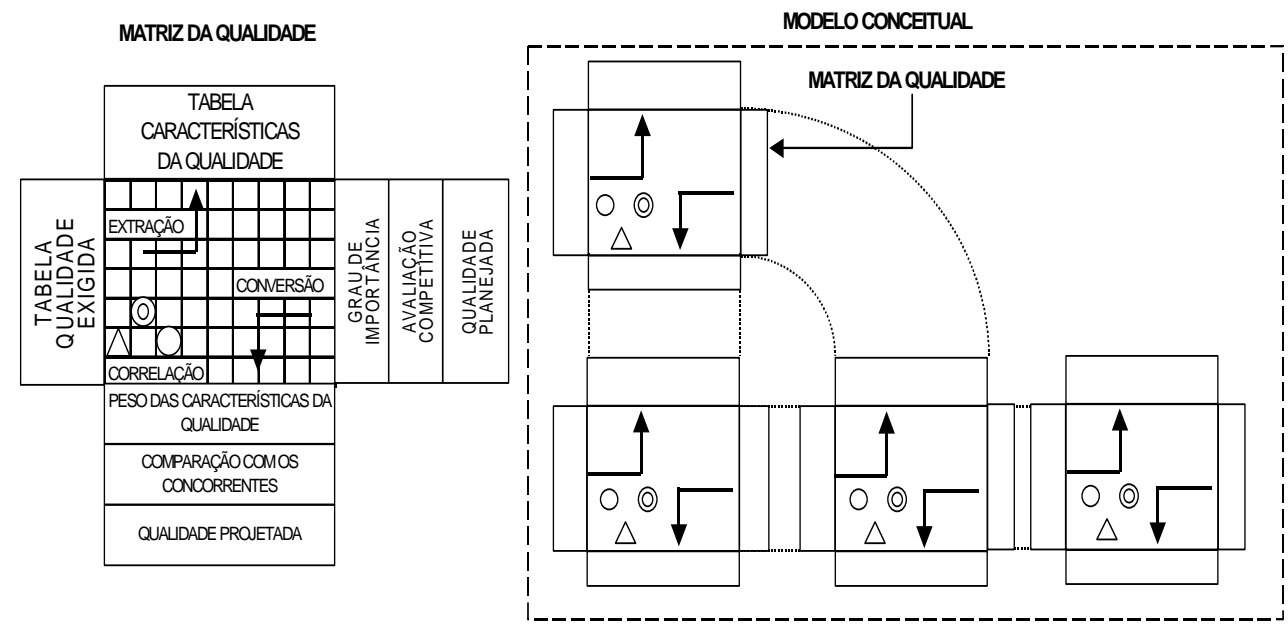

Figura 2 - Unidades Básicas de Trabalho do QD.

Dessa forma, o QFD visa auxiliar o estabelecimento de um mecanismo de duas partes. A primeira parte do mecanismo é o QD, em que a voz do cliente é desdobrada até chegar ao estabelecimento do valor dos parâmetros de controle dos processos. $\mathrm{O}$ segundo mecanismo é o desdobramento do trabalho através do QFDr.

O referencial teórico descrito possibilitou uma base teórica para que seja possível investigar e direcionar os estudos de caso descritos a seguir. Antes, entretanto, são apresentados os métodos e técnicas adotados no presente trabalho.

\section{MÉTODOS E TÉCNICAS DE PESOUISA}

A abordagem metodológica empregada para a condução das atividades de investigação desse artigo está baseada em estudo de casos que possuíam características específicas que seriam importantes para serem analisadas. Para YIN (2001), os estudos de caso representam a estratégia preferida quando surgem questões do tipo "como" e "por que", quando o pesquisador tem pouco controle sobre os eventos. Essa argumentação pode ser adotada na presente investigação, além do que o estudo de caso é também útil nas investigações exploratórias onde as variáveis ainda são desconhecidas e os fenômenos não são totalmente entendidos (VOSS et al., 2002). Esses autores complementam que os estudos de caso podem ainda ser úteis para propostas de construção de teorias, testes de teorias e refinamento/complemento de teoria. No caso específico desse trabalho, o propósito final é um refinamento da 
teoria, no sentido de entender melhor como o método QFD deve ser empregado nos processos estruturados de desenvolvimento tais como o stage-gate.

Pelo fato desta investigação buscar evidências práticas que possibilite atingir os objetivos do trabalho, os estudos de caso se enquadram de forma adequada como técnica de pesquisa. Entretanto, os estudos de caso têm o caráter exploratório, já que, se trata de uma familiarização inicial de investigação, da forma como ocorre a inserção do QFD no processo de desenvolvimento de produtos, o que é pouco explorado na literatura.

Os casos foram selecionados com base em trabalho anterior já concluído, no qual realizou-se um levantamento exploratório sobre o uso do QFD nas 500 maiores empresas brasileiras classificadas por vendas (CARNEVALLI, 2002). De acordo com esse trabalho, aproximadamente $19 \%$ das empresas analisadas utilizavam ou estavam implementando o QFD para desenvolver seus produtos. Os estudos de caso descritos mais a frente investigaram cinco casos práticos, que podem ser considerados como significativos, pois essas organizações demonstraram certa maturidade no uso do QFD, seja em função do tempo de implementação, aspectos exemplares na aplicação do método (por exemplo: uso de vários desdobramentos - qualidade e tecnologia, desenvolvimento de outras matrizes, além da matriz da qualidade, dentre outros. Desses casos, quatro deles possuíam publicação de artigos em que o QFD auxiliava de alguma forma o processo de desenvolvimento de produtos.

As empresas escolhidas como estudos de caso tiveram seus nomes colocados em anonimato devido a sua solicitação. Assim, cada empresa estudada assumiu nome codificado conforme a seqüência da investigação como: empresa A (caso no1), empresa B (caso no2), empresa C (caso no3), empresa D (caso no4) e empresa $E$ (caso no5).

Cada estudo de caso foi explorado sob a forma de entrevistas semi-estruturadas que consistia basicamente de duas perguntas: "como é o modelo estruturado de desenvolvimento de produto da empresa?" e "como o QFD é inserido nesse modelo?". Assim, através dessas duas perguntas básicas, o entrevistador tinha a liberdade de aprofundar mais sobre uma determinada resposta dada pelo entrevistado e fazer outras questões. Por exemplo, a questão 2, era complementada por questões do tipo: "em quais estágios de desenvolvimento o QFD é usado?", "quais atividades inerentes a aplicação do QFD são aplicadas nesses estágios?", "como é a operação do QFD?" (por exemplo, quais as exigências encontradas para a implantação do QFD e benefícios advindos da introdução do método no processo de desenvolvimento), "todos os desdobramentos do QFD sugeridos na literatura são feitos?", dentre outras.

Para registro dos dados, as entrevistas foram gravadas em fitas cassete, com um tempo médio de duração de 1h30min. Essas entrevistas foram conduzidas por uma equipe onde um membro dirigia as perguntas aos participantes, outros dois dialogavam com os participantes, complementando com outras questões e um outro observava e anotava quaisquer reações dos entrevistados. A Tabela 1 mostra os dados informativos das entrevistas. 
Tabela 1- Dados das Entrevistas

\begin{tabular}{|c|c|l|c|}
\hline EMPRESA & SETOR & \multicolumn{1}{|c|}{ PESSOAS ENTREVISTADAS } & $\begin{array}{c}\text { DURAÇÃO DA } \\
\text { ENTREVISTAS }(\mathrm{h})\end{array}$ \\
\hline EMPRESA A & AUTOMOBILÍSTICA & $\begin{array}{l}1 \text { - GERENTE DA QUALIDADE } \\
\text { 3- ENGENHEIROS DA QUALIDADE }\end{array}$ & $02: 30$ \\
\hline EMPRESA B & ALIMENTÍCIA & 1 - CONSULTOR - DEPARTAMENTO DE P\&D & $01: 30$ \\
\hline EMPRESA C & $\begin{array}{c}\text { MÁQUINAS E } \\
\text { EQUIPAMENTOS }\end{array}$ & $\begin{array}{l}1 \text { - GERENTE DE PROJETOS DE NOVOS PRODUTOS } \\
1 \text { - CONSULTOR DE ENGENHARIA E MATERIAIS }\end{array}$ & $01: 30$ \\
\hline EMPRESA D & EMBALAGENS & $\begin{array}{l}1 \text { - CONSULTORA DE DESENVOLVIMENTO DE NOVOS PRODUTOS } \\
\text { 2- ANALISTAS DE PROCESSOS }\end{array}$ & $01: 30$ \\
\hline EMPRESA E & METALURGIA & 1 - CHEFE DE DIVISÃO DE TECNOLOGIA & $01: 10$ \\
\hline
\end{tabular}

As entrevistas permitiram uma familiarização mais profunda com o tema em questão, através das informações e dados fornecidos. Entretanto, após a transcrição da gravação e análise inicial de algumas das entrevistas foi verificado que algumas das informações apresentadas necessitavam uma explanação mais detalhada. Assim, foi encaminhado para cada uma dessas empresas um e-mail a fim de que houvesse maiores esclarecimentos. Também foi feita uma análise documental como fonte de informação relativa às empresas estudadas, por meio de alguns documentos cedidos pelas empresas. Como destacado anteriormente, informações disponíveis na literatura que cita estudos nessas empresas também foram utilizados.

A análise dos dados foi feita tendo como base o referencial teórico de uso do QFD e processo de desenvolvimento de produtos, por meio do uso de referências que citam, mesmo de forma restrita, a aplicação do método nos estágios de desenvolvimento de produto. Das transcrições foram extraídos os dados necessários para fazer a análise, destacando as partes do texto com maior ou menor relação com os propósitos do trabalho. Assim, após essa extração foram construídos os textos de cada caso, que destaca, para cada empresa estudada, a intensidade de utilização do QFD nos estágios de desenvolvimento de novos produtos.

\section{RESULTADOS DO ESTUDO DE CASOS}

Como citado anteriormente, as empresas estudadas assumiram nomes codificados (empresa A, B, C, D e empresa E) e seus resultados serão apresentados com essa nomenclatura. $O$ ideal seria que todos os nomes fossem revelados, o que permitiria ao leitor um entendimento maior do contexto. Entretanto, para YIN (2001), há ocasiões em que o anonimato se faz necessário, salientando que uma das razões é que a divulgação do relatório final pode interferir nas ações subseqüentes das pessoas (ou empresas) que foram estudadas.

A apresentação de cada estudo de caso ficou estruturada da seguinte forma:

1) Caracterização da empresa: descreve o perfil geral da empresa, bem como sua tipologia e tipos de produtos fabricados, seguindo a classificação descrita por GRIFFIN \& PAGE (1996).

2) Modelo de desenvolvimento: neste item procurou-se investigar qual o modelo de estrutura de desenvolvimento de produtos usado e quais suas características 
básicas.

3) QFD na empresa: para esse item buscou-se compreender como a empresa se preparou para absorver o método, quais as exigências encontradas para a implantação e benefícios advindos do QFD no processo de desenvolvimento.

4) Inserção do QFD no modelo de desenvolvimento: este item tem grande importância, pois buscou-se através dele compreender como o QFD se integrava ao processo de desenvolvimento de novos produtos. Nesta investigação, procurou-se verificar se o QFD era utilizado de forma contínua ou parcial nos estágios de desenvolvimento de produto, com que intensidade.

A seguir é apresentado cada um dos casos investigados.

\subsection{Estudo de Caso no 1 - Empresa A}

A Empresa A é uma indústria fabricante de veículos pesados com sede fora do Brasil, cuja filial brasileira produz mais de 30 modelos de veículos, entre leves, médios, semi-pesados, pesados e extra-pesados, com múltiplas opções de motores. No Brasil, essa empresa se enquadra como a maior fabricante nesse segmento. A característica da empresa é prospectora, segundo uma análise realizada a partir da classificação de GRIFFIN \& PAGE (1996) e o tipo geral de processo ao qual os produtos são produzidos são de alto volume e de média para alta variedade.

\subsubsection{Modelo de Desenvolvimento}

A empresa possui um modelo estruturado de desenvolvimento de produtos criado em sua matriz, baseado em estágios e gates, similar ao descrito por COOPER (1993), utilizado tanto para projetos plataforma quanto para projetos derivativos. Esse modelo possui uma característica especial por ser regressivo, cujos principais desafios são o de tornar o produto acessível ao cliente em um menor tempo possível e o de ter a capacidade de produzir produtos que satisfaçam as necessidades dos clientes.

\subsubsection{QFD na Empresa}

O QFD foi introduzido na empresa em 1993, com o objetivo de auxiliar o processo de desenvolvimento de produtos, já que existia a necessidade de materializar o produto de acordo com as necessidades e expectativas do mercado. Segundo a empresa, muitos dos requisitos técnicos que a engenharia não considerava, o cliente revelava importante. Além disso, ocorriam conflitos entre os profissionais envolvidos no desenvolvimento do produto, quanto a certos requisitos, que na realidade o cliente não julgava com grande valor.

Durante o aprendizado sobre o método, nas fases iniciais de sua introdução, foi discutida a importância do QFD, não somente sobre a questão metodológica, mas 
também como tornar possível a operacionalização deste na fábrica, quais seriam os principais resultados possíveis e também as principais dificuldades. Quanto ao aprendizado relacionado ao QFD, a empresa considerou eficaz, mas na parte operacional apresentou algumas dificuldades, já que a utilização do método poderia trazer impactos no processo de desenvolvimento de novos produtos e com isso dificultar e alongar o ciclo de desenvolvimento. Entre as principais exigências para que o QFD atingisse o sucesso esperado na empresa seria vital o comprometimento da alta administração, assessoria externa com conhecimentos profundos sobre o método (fornecendo treinamento adequado por meio de exemplos práticos próximos aos vivenciados pela empresa), comprometimento de todas as pessoas envolvidas e que essas pessoas conhecessem antecipadamente algum conhecimento básico desse método.

O QFD na empresa faz parte de uma vasta variedade de métodos e ferramentas que podem ser utilizados durante o desenvolvimento e sua utilização não é compulsória. Além disso, a empresa não realiza todos os desdobramentos, como custos, confiabilidade e tecnologia (AKAO, 1990; 1996), ficando limitado apenas a matriz principal de desdobramento da qualidade.

Entretanto, para a empresa, a matriz é construída de forma muito abrangente, sendo que as informações geradas pelos clientes (qualitativamente), são convertidas em uma grande lista de qualidades exigidas. Para se ter uma noção da dimensão dessa matriz, para um determinado produto, a empresa relacionou uma lista de 130 itens de qualidades exigidas, extraindo-se posteriormente 275 itens de características da qualidade. A abrangência da matriz da qualidade permite à empresa utilizar alguns itens já correlacionados para um produto plataforma, para vários outros tipos de produtos derivativos. Por exemplo, um item já mensurado, quanto a potência de motor ou distância entre eixos de um produto plataforma, poderia ser utilizado como dados informativos para uma ampla gama de produtos derivativos.

Entre as vantagens que o QFD trouxe para a empresa durante o desenvolvimento de produtos estão: resolver impasses da qualidade exigida que a empresa acha importante, mas o cliente não, evidenciar as qualidades exigidas mais importante para o cliente e fortalecimento da engenharia simultânea.

\subsubsection{Inserção do QFD no Modelo de Desenvolvimento}

A inserção do QFD com o modelo regressivo ocorre em um dos primeiros no estágios, que é o estágio de investigação conceitual das especificações do produto, conforme mostrado na figura 3. Assim, o QFD é utilizado apenas como ferramenta de mensuração de mercado e análise da concorrência, por meio dos dados da matriz da qualidade. 


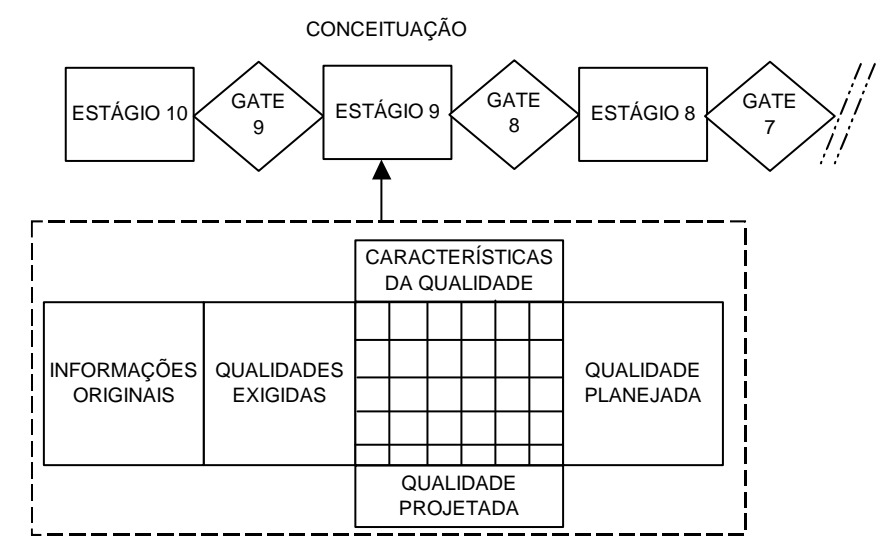

Figura 3 - Inserção do QFD no Modelo da Empresa A.

$\mathrm{Na}$ teoria apesar do modelo do QFD contemplar as quatro dimensões de desdobramento (qualidade, custo, tecnologia e confiabilidade), sua utilização pode ficar restrita a matriz da qualidade. Conforme evidenciado por CHENG et al. (1995), a utilização do QFD depende das metas estabelecidas pela empresa em relação ao produto. Assim, a empresa acaba por utilizar o QFD apenas como ferramenta de mensuração das informações específicas de mercado, pela matriz da qualidade.

OHFUJl et al. (1997) destacam que o importante no estabelecimento da matriz da qualidade é a sua abrangência. Como a empresa A utiliza a matriz principal de forma bastante ampla, possibilitando uma extensa lista de qualidades exigidas e características da qualidade, que pode ser utilizado para uma variedade de linhas de produtos, confirma-se então as argumentações desses autores.

\subsection{Estudo de Caso no 2 - Empresa B}

A Empresa B é uma indústria processadora de alimentos que se enquadra entre as maiores do Brasil, exportando para mais de 60 países. Essa empresa possui uma participação interna de $63 \%$, possuindo característica prospectora, segundo a classificação de GRIFFIN \& PAGE (1996), desenvolvendo produtos "novo para o mundo", "novo para companhia" e "extensões de linha". Além disso, o tipo geral de processo utilizado pela empresa para a fabricação de seus produtos é o de alto volume e média variedade de produção.

\subsubsection{Modelo de Desenvolvimento}

A empresa iniciou a implantação do controle da qualidade total (TQC) em 1991 e desde então tem utilizado o ciclo de Deming (PDCA) para permear todas as atividades relacionadas ao desenvolvimento de produtos, segundo CAMPOS (1992). Então, baseando-se nesse ciclo, a empresa estabeleceu um processo estruturado de desenvolvimento através dos seguintes estágios: estudo de oportunidade (plan), 
desenvolvimento (do), implantação (check), lançamento e acompanhamento (act). Cada um desses estágios é desdobrado em até três níveis para chegar às atividades das áreas funcionais correspondentes da empresa.

\subsubsection{QFD na Empresa}

Em 1993, a empresa iniciou estudos para que um nvo método objetivasse a qualidade dos produtos desde o projeto até a produção, levando em consideração as necessidades e expectativas do cliente. Para SHIBA et al. (1997) e OHFUJI et al. (1997), essa visão de focar a empresa nas necessidades e desejos do cliente está relacionada ao conceito market-in, cujo qual, prioriza o cliente no desenvolvimento dos produtos. Assim, houve a compreensão de que o QFD poderia ser o método a atender esse propósito.

A introdução ao QFD pela empresa foi realizada com o auxílio externo, que forneceu uma grande estrutura para que a implantação do QFD fosse concretizada de forma eficaz. Essa assessoria foi considerada pela empresa como um dos pontos fundamentais para que a empresa obtivesse sucesso na implantação no método. Além disso, outros pontos-chave foram considerados determinantes para o sucesso na implantação, tais como: o apoio irrestrito da alta administração, a formação de uma excelente equipe de implantação com pessoas com bom trânsito interno, além de disponibilização de recursos financeiros.

Apesar da empresa seguir o modelo das quatro ênfases, que propõe o desdobramento da qualidade, confiabilidade, custos e tecnologia (conforme AKAO, 1990; 1996), a aplicação do QFD para produtos da empresa ficou limitada ao desdobramento da qualidade. O ponto preponderante em não aplicar outros desdobramentos, está na dificuldade de aliar a teoria com a prática da empresa, uma dificuldade relativamente comum nas organizações que aplicam o QFD.

O desdobramento da qualidade é iniciado através da obtenção das informações de mercado, ou seja, os dados originais, por meio da escolha do público-alvo e levantamento de dados por pesquisas de mercado. Em seguida, a empresa transforma esses dados originais em itens exigidos, para finalmente definir as qualidades exigidas. Para OHFUJI et al. (1997), a conversão direta dos dados primitivos para qualidade exigida, às vezes se torna um processo difícil, desta forma usa-se um meio intermediário, que são os itens exigidos, para facilitar o processo de tratamento dos dados da voz do cliente e obter melhor compreensão sobre esse processo.

Após o estabelecimento das qualidades exigidas, a empresa elabora a matriz da qualidade, estabelecendo a qualidade planejada e a qualidade projetada. Para a matriz ser finalizada, a empresa constrói um protótipo de produto para verificar se as qualidades exigidas pelos clientes foram plenamente atendidas. A partir da realização da matriz da qualidade, a empresa pode realizar outras matrizes conforme a necessidade, estabelecendo assim o modelo conceitual.

O número de matrizes desenvolvidas pela empresa pode atravessar praticamente todo o desenvolvimento, desde a matéria-prima, processos e parâmetros de controle. Além disso, a empresa utiliza o QFD para levar as especificações técnicas de projeto para o chão-de-fábrica, através do Padrão Técnico de Processo (PTP), que é 
desdobrado em processos operacionais pelos supervisores da linha com os operadores. Para CHENG et al. (1995), o PTP é o documento final do trabalho de QFD, pois, é para o PTP que o QD e o QFDr devem convergir.

Entre os benefícios conquistados pela empresa com relação ao QFD estão: tornar o processo de desenvolvimento mais formal, melhorar a comunicação entre os departamentos envolvidos, facilitar a aplicação de outras ferramentas (análise descritiva quantitativa, teste afetivo e análise sensorial) e fornecer visão sobre os concorrentes. A empresa considera também que o QFD trouxe uma redução do ciclo de desenvolvimento de produtos, não mensurado, mas que pode ser obtido indiretamente por meio de outras vantagens conquistadas.

Apesar da empresa considerar o QFD muito importante, sua utilização dentro do processo de desenvolvimento não é obrigatória. Assim, dependendo do tipo de projeto e complexidade, a empresa tem a opção de utilização ou não do método.

\subsubsection{Inserção do QFD no Modelo de Desenvolvimento}

A figura 4 mostra a inserção do QFD no modelo da empresa. De acordo com o presente estudo, o QFD é iniciado no estágio 1 através do levantamento das qualidades exigidas. No estágio 2 ocorre o projeto da qualidade, por meio dos desdobramentos das qualidade exigidas em características da qualidade auxiliando no desenvolvimento do produto e do processo (características da qualidade do processo intermediário e características da qualidade da matéria-prima). Finalmente, no estágio 3 , o QFD é utilizado para levar as especificações do projeto para o chão-de-fábrica, com o auxílio do PTP.

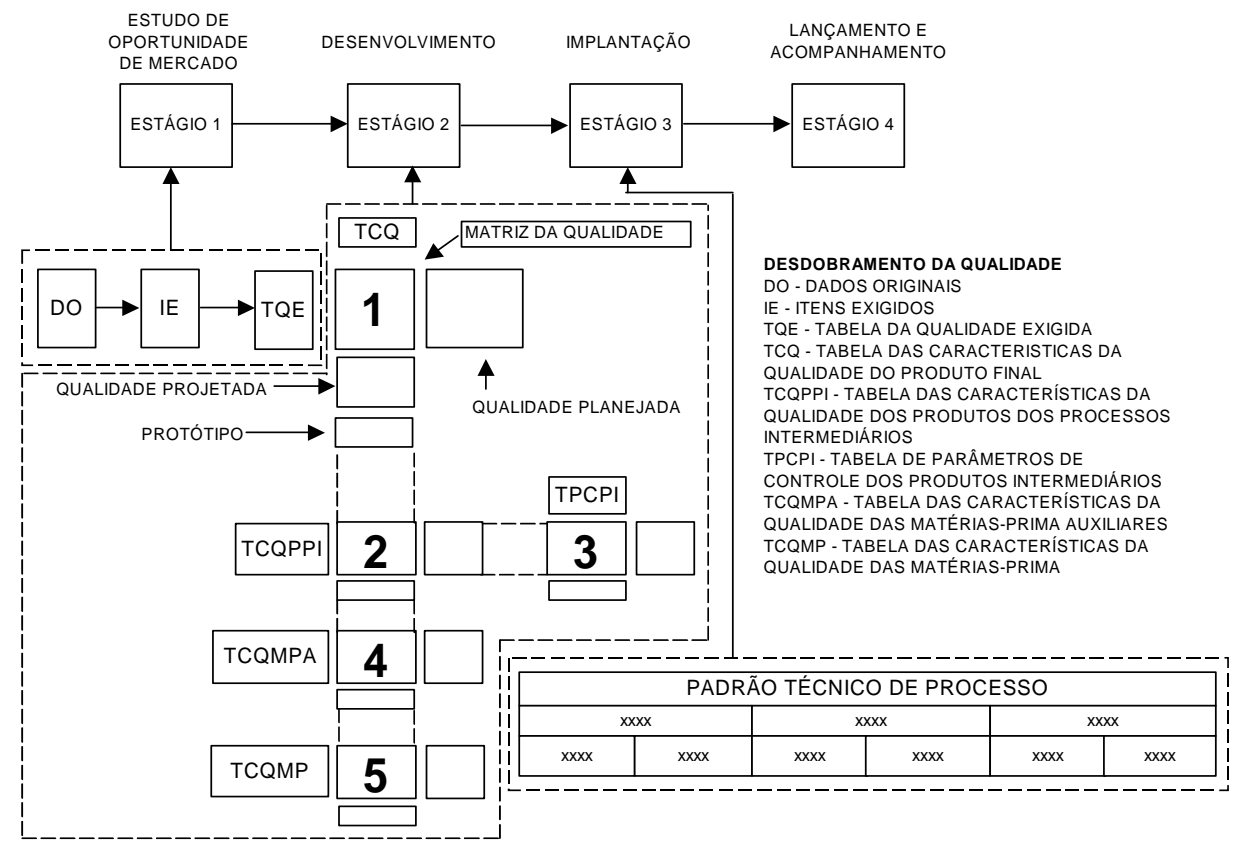

Figura 4 - Inserção do QFD no Modelo de Desenvolvimento da Empresa B. 


\subsection{Estudo de Caso no 3 - Empresa C}

A empresa $C$ é uma fabricante líder mundial de máquinas e equipamentos de construção e mineração, com sede no exterior mas com uma planta industrial no Brasil. Esta empresa é caracterizada como prospectora, (classificação conforme GRIFFIN \& PAGE, 1996), desenvolvendo linhas de produtos "novo para o mundo" e "extensões de linha". A empresa C possui uma grande variedade de produtos plataformas e derivativos, entre os quais estão: motoniveladoras, carregadeiras, tratores de esteira, onde detém uma participação de mercado externo de 65\% (exporta para mais de 100 países) e interno de $35 \%$. O tipo de processo de produção de produtos é de médio volume e média variedade.

\subsubsection{Modelo de Desenvolvimento}

A empresa C possui um modelo estruturado de desenvolvimento de produtos criado em sua matriz americana, baseado em estágios e gates. Esse modelo possui cinco estágios (Conceito, Desenvolvimento, Produção, Lançamento e Avaliação Final) e quatro gates, divididos em A (Primeira Revisão), P (Prototype), R (Readiness) e S (Shipping).

O processo é caracterizado como de longo prazo para projetos plataformas, sendo que o ciclo de desenvolvimento pode exceder dez anos. Dentro desse ciclo, existem revisões a cada três anos para estabelecer metas para prazos mais curtos. Invariavelmente, esses projetos sempre nascem na matriz e depois migram para cada unidade, para que sejam desenvolvidos os projetos derivativos de acordo com as necessidades dos clientes, características da região utilizada pelo produto e regulamentações ambientais e de segurança que devem ser cumpridas.

O principal desafio da empresa relacionado ao desenvolvimento de produtos é conseguir reduzir o ciclo de desenvolvimento, para que o impacto das informações geradas pelos clientes no início do desenvolvimento varie muito pouco quando ocorrer o lançamento do produto no mercado, principalmente devido ao longo lead-time de desenvolvimento de novos produtos.

\subsubsection{OFD na Empresa}

O QFD foi introduzido na companhia em 1988, juntamente com uma série de outros métodos e ferramentas de gestão e garantia da qualidade, no intuito de auxiliar no diagnóstico das necessidades dos clientes nos momentos iniciais do processo de desenvolvimento. $O$ treinamento foi realizado pela própria empresa através de seu grupo de suporte interno, que forneceu os princípios básicos do método. 
A empresa objetivava conceber tipos de produtos padronizados que fossem comuns a maioria dos países que tivessem o interesse em adquirí-los. Entretanto, para a empresa, a padronização é muito difícil, já que existem muitas variáveis a ser consideradas dentre as quais: os tipos de solos, regulamentações ambientais e de segurança, além das necessidades específicas de clientes regionais. A empresa pode perceber que o QFD poderia auxiliar na solução dessas variáveis para cada tipo de produto.

Foi identificado nessa empresa que existem muitos fatores exigidos que devem ser exigidos implantação do método, tais como: comprometimento das pessoas envolvimento das pessoas envolvidas, apoio da alta administração, escolha eficaz das pessoas envolvidas, treinamento adequado através de consultoria externa e estrutura organizacional específica para a equipe de QFD.

O QFD é utilizado pela empresa apenas para relacionar as necessidades dos clientes com as especificações (características da qualidade) por meio da matriz da qualidade. As informações colhidas no mercado para o estabelecimento das qualidades exigidas são realizadas por meio de pesquisas qualitativas de mercado, através de clientes potenciais, representantes da empresa e operadores de máquinas. Quando essa matriz é finalizada a empresa procura obter um feedback do cliente para verificar se as qualidades exigidas foram atingidas. Geralmente, esse resultado final é apresentado sob forma de um modelo virtual. A importância dos modelos virtuais também são descritos por COOPER (1993) no "projeto conceitual" e também por CLARK \& WHEELWRIGHT (1993) no "design-build-test". A utilização do QFD pela empresa não é obrigatória, entretanto, devido aos benefícios obtidos com essa ferramenta o objetivo é torná-la obrigatória em um futuro próximo, mas esta deverá estar limitada apenas a primeira matriz, que é a matriz da qualidade.

Para a empresa a principal vantagem conquistada com o QFD, está na eliminação de dúvidas relacionadas ao tipo de produtos a serem desenvolvidos para certas regiões evitando mudanças radicais nos produtos plataformas. Com isso, o produto é desenvolvido com uma qualidade maior de percepção de valor pelo cliente e também com um menor custo final de produto.

\subsubsection{Inserção do QFD no Modelo da Empresa}

A inserção do QFD com o modelo estruturado da empresa ocorre no primeiro estágio do desenvolvimento de novos produtos, que é o desenvolvimento conceitual do produto. A figura 5 mostra a matriz da qualidade inserida no modelo da empresa. 


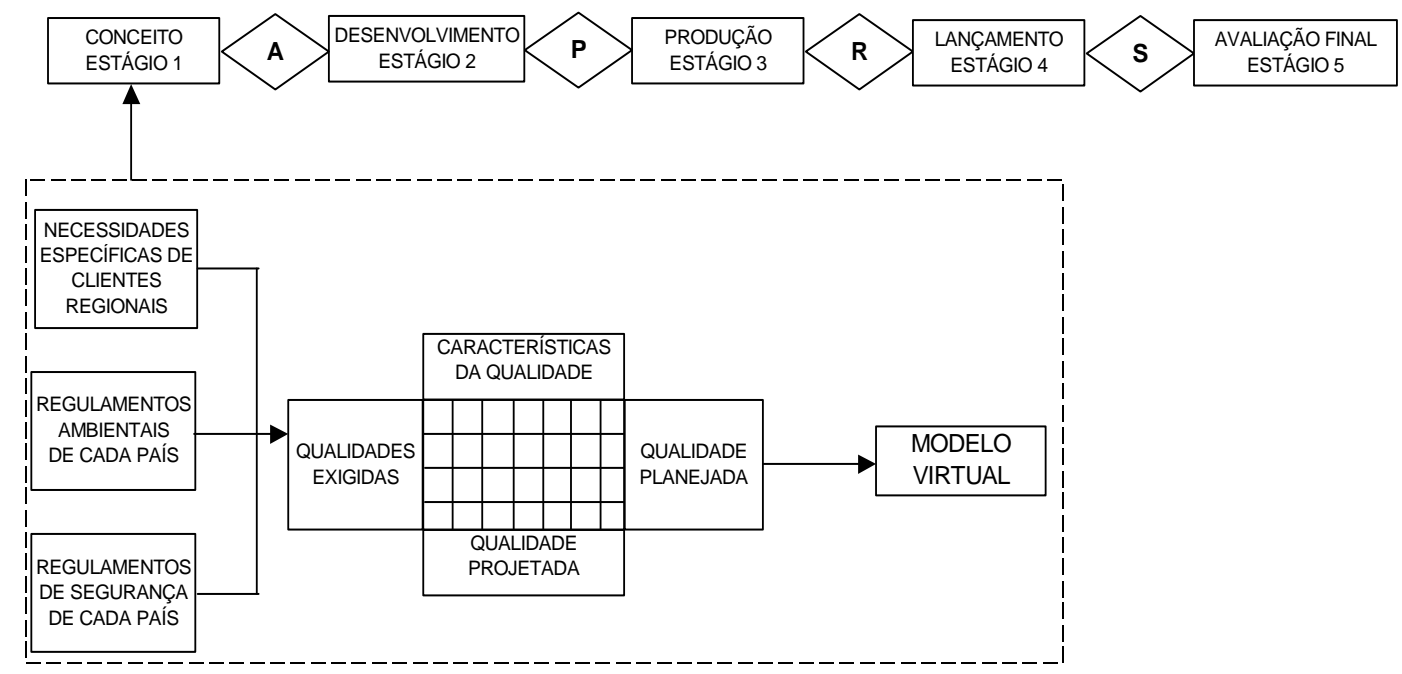

Figura 5 - Inserção do QFD no Modelo de Desenvolvimento da Empresa C.

\subsection{Estudo de Caso no 4 - Empresa D}

O quarto caso é de uma empresa fabricante de filmes flexíveis para embalagens, com característica analista, que desenvolve produtos "novo para a companhia" e "extensões de linha", segundo a classificação de GRIFFIN \& PAGE (1996), com uma participação de mercado interno em torno de 35\%. O tipo de processo para produtos é o volume muito alto e alta variedade.

\subsubsection{Modelo de Desenvolvimento}

A empresa possui desde 1994 a certificação do seu sistema da qualidade conforme a norma ISO 9001 e vem reestruturando seu processo de gestão de desenvolvimento de produtos. Foi então criado um modelo de desenvolvimento baseado em 6 estágios (Proposta Básica, Plano Preliminar, Plano Operacional, Desenvolvimento Fase Teste 1, Desenvolvimento Fase Teste 2 e Conclusão do Projeto) e cinco gates (denominados na empresa de "filtros").

Entretanto, o modelo apresentava algumas dificuldades para a execução de projetos como a necessidade de atender satisfatoriamente as necessidades do cliente desde os momentos iniciais, como também, dependência excessiva de pessoas-chave com relação ao desenvolvimento. Para AKAO \& MAZUR (1998), o QFD oferece um caminho para auxiliar na solução dessas dificuldades apresentadas e também estabelece um importante auxílio no cumprimento de normas como a ISO 9001.

\subsubsection{QFD na Empresa}


A empresa pode constatar que o QFD poderia auxiliar na gestão de desenvolvimento de produtos e estabelecer um padrão geral para conduzir projetos. Entre as varias exigências da empresa para que a implantação pudesse obter sucesso estavam: apoio da alta administração, conhecimento sobre o método, apoio externo, e comprometimento das pessoas envolvidas.

Atualmente, a empresa tem utilizado o QFD, através do desdobramento da qualidade, para auxiliar na gestão de desenvolvimento de produtos e na busca de um padrão para conduzir projetos. Entre outros benefícios conquistados com o QFD estão: tornar o processo de desenvolvimento mais formal, ajudar na aplicação de outras ferramentas (diagrama de Ishikawa, sete ferramentas de planejamento, sete ferramentas da qualidade e melhoria das pesquisas de mercado), disseminação e nivelamento do conhecimento e melhoria da comunicação multifuncional.

\subsubsection{Inserção do QFD no modelo de Desenvolvimento}

A inserção do QFD com o modelo da empresa ocorre em praticamente todos os estágios, evidenciando uma tendência de que o QFD seja incorporado permanentemente com o modelo, tornando compulsório seu uso, conforme ilustrado na figura 6. A perspectiva futura é que a empresa consiga desenvolver um modelo de QFD que seja padrão para a aplicação na maioria de produtos desenvolvidos pela empresa.

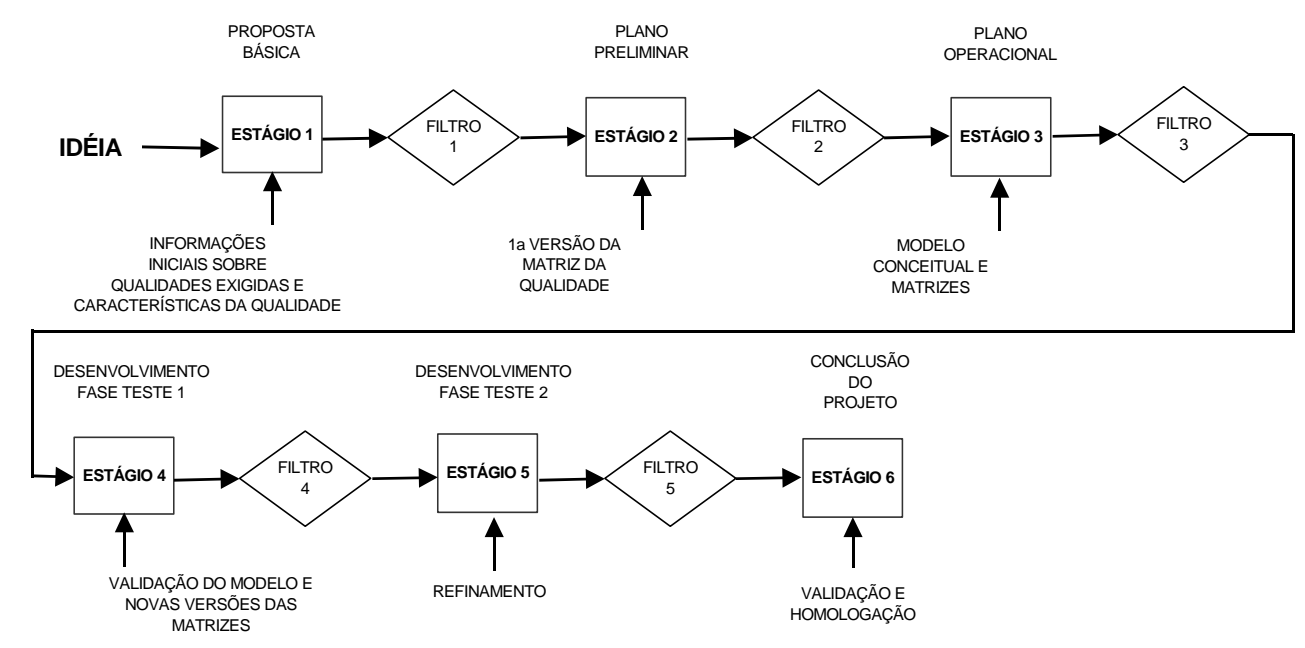

Figura 6 - Inserção do QFD no modelo de Desenvolvimento da Empresa D.

\subsection{Estudo de Caso no 5 - Empresa E}


A Empresa E é uma indústria que se dedica a metalurgia do cobre, outros metais primários e reaproveitamento de subprodutos. Essa empresa possui uma participação de mercado interno de $70 \%$. Com características analista (segundo a classificação de GRIFFIN \& PAGE, 1996), essa empresa produz produtos "novo para a companhia" e o tipo de produção para seus produtos é o de volume alto e baixa variedade.

\subsubsection{Modelo de Desenvolvimento}

De acordo com as informações investigadas, a empresa possui um modelo não estruturado de desenvolvimento de novos produtos dividido em Planejamento Estratégico, Concepção, Implantação e Lançamento. Esse modelo, por não possuir estrutura documentada e formalizada, resulta em constantes perdas de controle durante o desenvolvimento e dependência excessiva de pessoas-chave para cada tipo de projeto.

\subsubsection{QFD na Empresa}

O QFD surgiu na empresa como uma das etapas do programa de qualidade do TQC (Total Quality Control ou Gestão para a Qualidade Total), sendo observado que esse método poderia ser uma possível alternativa para trazer para a empresa uma estrutura eficiente e formalizada para o desenvolvimento de produtos e melhoria de produtos existentes.

Assim, o QFD foi introduzido na empresa ainda em meados da década de 90 (1994), desenvolvendo um projeto piloto. O resultado final desse produto trouxe uma melhoria significativa para a qualidade do produto da empresa, não apenas confirmando a satisfação deste pelo mercado, mas também permitiu que aumentasse sua fatia de participação. $O$ aprendizado e resultados adquiridos com o projeto piloto possibilitaram que o QFD fosse aplicado em um outro produto da empresa.

Para que o QFD fosse implantado na empresa foram consideradas as seguintes exigências: comprometimento de todos os envolvidos e crença da importância do método, apoio irrestrito da alta administração, aprendizado através de uma consultoria com experiências em produtos similares ao da empresa.

Após o sucesso com o projeto-piloto, a empresa determinou que fosse criado um sistema de padrão utilizando o QFD como referência para o desenvolvimento de novos produtos. Entretanto, considerou que o método era muito complexo para ser assimilado pelos funcionários.

Apesar da empresa ainda ter uma limitação do número de produtos desenvolvidos com o QFD, os benefícios advindo com sua utilização podem ser observados, como: criar um indicador de qualidade capaz de posicionar o produto no mercado, diminuição do ciclo de desenvolvimento do produto, aumento da qualidade e confiabilidade, melhoria do trabalho em grupo, melhor visão sobre os concorrentes e melhoria da comunicação interfuncional. 


\subsubsection{Inserção do QFD no Modelo de Desenvolvimento}

Com a experiência adquirida com o QFD, a empresa criou um modelo de desenvolvimento baseado no QFD, mas que não exige que todas as suas etapas sejam cumpridas. Esse modelo de desenvolvimento de novos produtos faz uma avaliação de cada projeto e determina quais as etapas importantes deverão ser realmente executadas. Assim, a empresa considera imprescindível a utilização da matriz da qualidade para o desenvolvimento de todos os produtos, mas deixa a opção de montar as outras matrizes conforme o tipo de produto. A figura 7 mostra como o QFD é inserido no processo não estruturado da empresa.

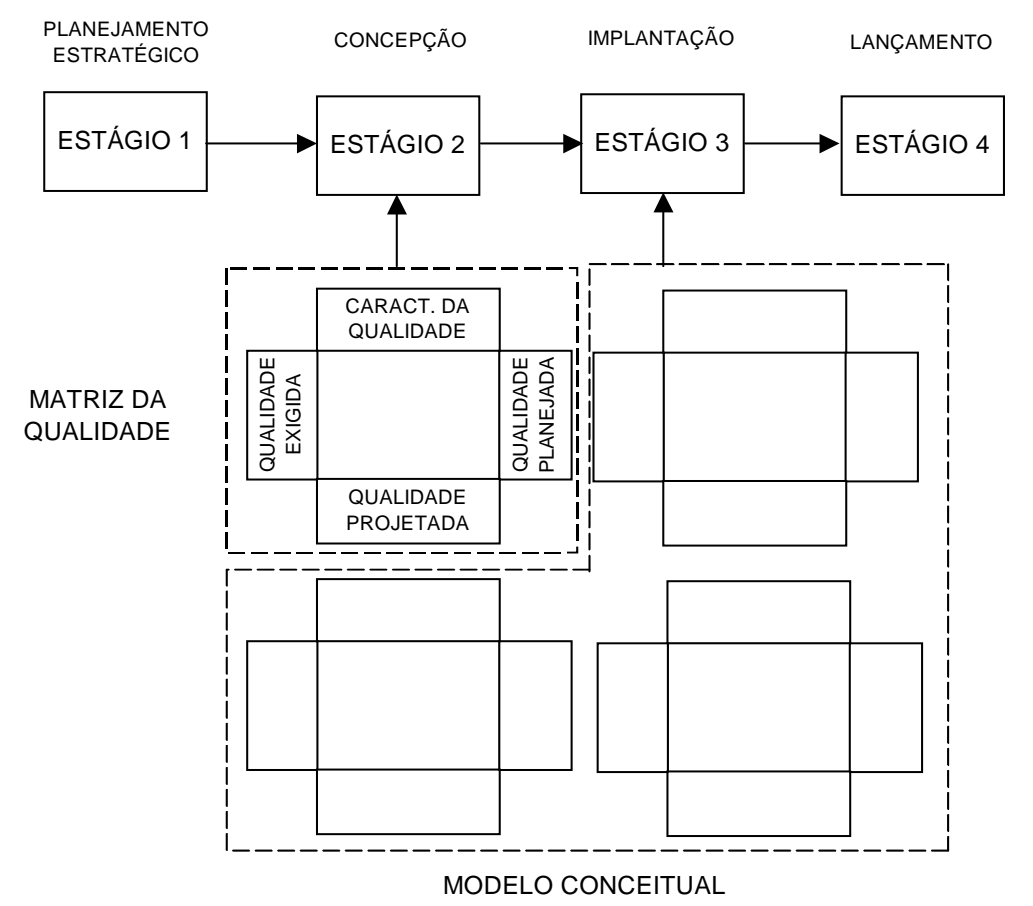

Figura 7 - Inserção do QFD no modelo de Desenvolvimento da Empresa E.

\subsection{Síntese dos Resultados}

A tabela 2 sintetiza as variáveis comparativas entre cada caso investigado. A síntese apresentada na tabela mostra os diferentes perfis das empresas pesquisadas, assim como suas características de inovação de produtos e também tipo de processo de produção (volume e variedade) que são levados em consideração durante o desenvolvimento. Além disso, está evidenciado na tabela, o tipo de estrutura de processo de desenvolvimento de produtos, que cada empresa utiliza. A partir dessas características, o QFD pode ou não ser utilizado. 
Tabela 2 - Comparação entre cada caso investigado.

\begin{tabular}{|c|c|c|c|c|c|c|c|c|c|}
\hline \multirow{2}{*}{ EMPRESA } & \multirow{2}{*}{$\begin{array}{c}\text { TIPO } \\
\text { DE } \\
\text { EMPRESA }\end{array}$} & \multirow{2}{*}{$\begin{array}{c}\text { CARACTERISTICA } \\
\text { DA } \\
\text { EMPRESA }\end{array}$} & \multicolumn{2}{|c|}{$\begin{array}{c}\text { TIPO DE PROCESSO } \\
\text { DE PRODUÇÃO }\end{array}$} & \multirow{2}{*}{$\begin{array}{c}\text { PROCESSO } \\
\text { DE } \\
\text { DESENVOLVIMENTO }\end{array}$} & \multirow{2}{*}{ USO DO QFD } & \multirow{2}{*}{\begin{tabular}{|c} 
USO DE \\
OUTRAS MATRIZES \\
ALÉM DA MATRIZ \\
DA QUALIDADE \\
\end{tabular}} & \multirow{2}{*}{\begin{tabular}{|c|} 
USO \\
DE OUTROS \\
DESDOBRAMENTOS \\
\end{tabular}} & \multirow{2}{*}{$\begin{array}{c}\text { FASE DO } \\
\text { PROCESSO } \\
\text { QUE O QFD } \\
\text { É INSERIDO } \\
\end{array}$} \\
\hline & & & VOLUME & VARIEDADE & & & & & \\
\hline A & AUTOMOBILISTICA & PROSPECTORA & ALTO & MÉDIAVALTA & ESTRUTURADO & OPCIONAL & \begin{tabular}{|c|} 
NÃO \\
\end{tabular} & NÃO & INICIAL / 1 ESTÁGIO \\
\hline B & ALIMENTÍCIA & PROSPECTORA & ALTO & MÉDIA & SEMI-ESTRUTURADO & OPCIONAL & SIM & NÃO & VÁRIAS / 3 ESTÁGIOS \\
\hline C & $\begin{array}{c}\text { MÁQUINAS E } \\
\text { EQUIPAMENTOS } \\
\end{array}$ & PROSPECTORA & MÉDIO & MÉDIA & ESTRUTURADO & OPCIONAL & NÃO & NÃO & INICIAL / 1 ESTÁGIO \\
\hline $\mathrm{D}$ & EMBALAGENS & ANALISTA & MUITO ALTO & ALTA & SEMI-ESTRUTURADO & COMPULSÓRIC & SIM & NÃO & VÁRIAS / 5 ESTÁGIOS \\
\hline $\mathrm{E}$ & METALURGIA & ANALISTA & ALTO & BAIXA & NÃO ESTRUTURADO & OPCIONAL & SIM & NÃO & VÁRIAS / 2 ESTÁGIOS \\
\hline
\end{tabular}

De acordo com os resultados indicados na tabela 2, a utilização do QFD não parece ter relação com o grau de inovação de produtos e com o tipo de processo de produção, já que, os resultados não foram determinantes para a utilização maior ou menor do número de matrizes do QFD. Entretanto, para o tipo de estrutura do processo de desenvolvimento (coluna 6), o uso do QFD parece ter alguma relação, como pode ser visto, nos casos das empresas $A$ e $C$, que possuem um processo estruturado de desenvolvimento. Assim, nota-se que estas não dependem tanto do uso do QFD, quanto àquelas que possuem processos semi-estruturados e não estruturado, como no caso das empresas B, D e E. Mesmo considerando que a investigação do presente trabalho considera múltiplos casos, entende-se que o grau de generalização dos resultados (validade externa) é limitado, ou seja, não é possível afirmar com segurança as possíveis relações de causa e efeito citadas anteriormente. No entanto, considera-se que o presente trabalho evidencia esses aspectos, isto, é pode haver uma relação entre o uso mais extensivo do método e a estruturação do processo de desenvolvimento (inversamente proporcional, embora sem identificar a intensidade dessa relação). De maneira similar, não é possível afirmar com segurança que as características de inovação de produtos e também tipo de processo de produção podem estar associadas à utilização do método. Mais uma vez, considera-se que o presente trabalho suscita pontos importantes quanto ao uso do QFD, mas que, embora com evidências que podem ser consideradas como significativas, necessita de maior aprofundamento com estudos nesse sentido. Não obstantemente, o trabalho levanta alguns pontos conclusivos, destacados a seguir.

\section{Conclusões}

Um primeiro ponto conclusivo no presente trabalho, de acordo com as evidências dos casos, é que a inserção do QFD no processo de desenvolvimento de produtos depende da definição estratégica relacionada ao QFD neste processo, isto é, de quanto a empresa se empenha na sua introdução, conforme as necessidades que acredita. Assim, se uma empresa busca usar o QFD apenas com o propósito de mensuração de mercado e análise dos principais concorrentes, o método pode ser utilizado parcialmente por meio da matriz da qualidade. Porém, nota-se que esta matriz é elaborada da forma mais completa possível, considerando uma grande quantidade itens de qualidade exigida e características da qualidade.

No levantamento das qualidades exigidas as informações podem ser tanto quantitativas (empresa B), por meio da consulta de um grande número possível de 
clientes, quanto qualitativas (empresa $A$ e empresa $C$ ), por meio da identificação de clientes potenciais selecionados. Normalmente, quando o QFD é utilizado dessa forma, sua inserção no processo de desenvolvimento acaba ficando limitada a um ou mais dos estágios iniciais do processo de desenvolvimento. Ademais, como destacado anteriormente, a adoção apenas da matriz da qualidade mostrou ser uma possibilidade para as empresas que já possuem um modelo estruturado para desenvolver produtos, como visto na empresa $A$ e a empresa $C$, de maneira combinada ou não com os argumentos destacados no parágrafo anterior.

Entretanto, a utilização apenas da matriz da qualidade pode restringir o número de benefícios do QFD, mas não necessariamente prejudicar o método. Nota-se, portanto que, empresas que conhecem mais profundamente o QFD, como um método que pode ser aplicado ao longo do processo de desenvolvimento de produto, acabam explorando mais seu potencial de benefícios, conforme sugerido pelos resultados encontrados nas empresas B, D e E.

Para as empresas que não possuem processo estruturado de desenvolvimento e que buscam um meio para a estruturação (empresa B, empresa D e empresa E), o QFD pode ser empregado trazendo, inclusive, uma maior robustez no processo de desenvolvimento de novos produtos. Nesse caso, entretanto, o QFD deve ser mais completo, utilizando para isso várias matrizes, estendendo sua aplicação para além da matriz da qualidade.

Nos casos investigados neste artigo, nenhuma empresa realizou mais de um desdobramento do QFD, estando presente o desdobramento da qualidade, embora de forma muito limitada, o desdobramento da tecnologia. Essa investigação, no entanto, foi incapaz de determinar o motivo da não aplicação de outros desdobramentos. Apenas para o caso da empresa $B$, foi observado a falta de conhecimento em aplicar 0 desdobramento de custos para seus produtos, apesar de seu interesse. Assim, um ponto conclusivo importante é que a utilização extensiva do método (com vários desdobramentos), não se concretizou no nível empírico, diferentemente do que é usualmente apontado no nível teórico, divulgado pela literatura.

$\mathrm{Na}$ investigação dos casos foi verificado também um ponto contrastante relacionado ao ciclo de desenvolvimento de produtos. A empresa $A$, que utiliza apenas a matriz da qualidade, demonstrou grande preocupação com relação a complexidade do método, que poderia trazer impactos para o processo e com isso alongar o ciclo total de desenvolvimento de produtos. Porém, a empresa $B$ e empresa $D$, que utilizam mais de uma matriz do QFD, interagindo durante o processo de desenvolvimento, salientaram que o QFD foi capaz de reduzir o ciclo total do produto. Apesar de não ser mensurado formalmente no presente trabalho, esse resultado foi observado pelas empresas através dos diversos benefícios alcançados com o método.

Com relação ao aprendizado sobre o método, a empresa $B$, argumentou que devem existir meios que garantam treinamentos periódicos para os funcionários. Isso faz com que o conhecimento adquirido anteriormente com o método não se perca com o tempo, e assim, possa auxiliar constantemente e aperfeiçoar o processo de desenvolvimento de produtos. Uma das propostas para este desafio, é que a própria empresa poderia se incumbir da reciclagem, oferecendo treinamento interno através das pessoas que já conheçam e possuam experiência com o método. Além disso, o QFD já desenvolvido com outros produtos da empresa poderia ser utilizado como forma de aperfeiçoamento do aprendizado. 
Por se tratar de um estudo exploratório inicial, os resultados obtidos nessa investigação necessitam de maior aprofundamento, a fim de que se possam confirmálos e aprofunda-los, bem como poderia também abordar outros aspectos relevantes não investigados nesse trabalho. Nesse sentido, vários estudos podem ser realizados a partir dos resultados encontrados nessa investigação, tais como:

- Escolher um dos estudos de caso apresentado e a partir dele uma nova investigação em profundidade poderia ser realizada considerando, inclusive, um estudo longitudinal para verificar como ocorre a integração do QFD no processo de desenvolvimento de produtos durante sua evolução em termos de utilização;

- Determinar o motivo pelo qual os outros desdobramentos do QFD no desenvolvimento de produtos não são freqüentes, conforme demonstrado nesse artigo, diferentemente do que é divulgado na teoria sobre o método;

- Estudar uma forma com o método do QFD pode auxiliar no levantamento das qualidades exigidas para produtos que somente estarão disponíveis no mercado depois de um longo prazo, como por exemplo: 5 anos (empresa A) ou 10 anos (empresa C).

\begin{abstract}
In the search for improving product development practices, new approaches have been applied for developing new products. Among the approaches applied by companies are the structured development process. However, these processes demand that other methods should complete them, like QFD (Quality Function Deployment). Its objective is to translate customer demands into product specifications. In this sense, the objective of this article is to better understand, through multiple case studies, how companies are using QFD within their product development process. It has been studied five companies which apply QFD in their structured product development process. Data and information were gathered by using semi-structured interviews and company documents. The work presents the results of each investigated company and concludes that QFD within product development process depend son the strategic definition associated to the use of the method.
\end{abstract}

Key-words: Product development, Quality Function Deployment, QFD

\title{
REFERÊNCIAS
}

AKAO, Y. Quality function deployment: integrating requirements into product design. Pd, Oregon: Productivity Press. 1990. 369p.

AKAO, Y. Introdução ao desdobramento da qualidade. Belo Horizonte: Fundação 
Christiano Ottoni, 1996. 179p.

AKAO, Y. QFD: past, present, and future. International Symposium on QFD, Linköping, 1997. Disponível em: <http://www.qfdi.org/QFD_History.pdf>. Acesso em 10 set. 2002.

AKAO, Y; MAZUR, G.H. Using QFD to assure QS 9000 compliance. ISQFD'98 Sydney, 1998. Disponível em: <http://www.mazur.net/works/qs9000_compliance_with_qfd.pdf>. Acesso em 10 jan. 2003.

BAXTER, M. Projeto do produto: guia prático para design de novos produtos. 2. ed. Editora Edgard Blücher Ltda, 2000. 260p.

CAMPOS, F.V. TQC: controle da qualidade total (no estilo japonês). Belo Horizonte, Mg. Fundação Christiano Ottoni, Escola de Engenharia da UFMG. Rio de Janeiro: Bloch Editores, 1992. 220p.

CARNEVALLI, J.A. Estudo exploratório sobre o uso do QFD nas 500 maiores empresas no Brasil. 2002. 148p. Dissertação (Mestrado em Engenharia de Produção) - Universidade Metodista de Piracicaba, Piracicaba.

CHENG, L.C. et al. QFD: planejamento da qualidade. Belo Horizonte: Fundação Christiano Ottoni, 1995. 260p.

CLARK, K.B.; WHEELWRIGHT S.C. Managing new product and process development. New York: The Free Press, 1993. 896p.

COOPER, R.G. Winning at new products: accelerating the process from idea to launch. 2. ed. Reading: Addison-Wesley Publishing, 1993. 358p.

COOPER, R.G.; EDGETT S.J.; KLEINSCHMIDT E.J. Optimizing the stage gate process: what best practice companies are doing. Part1, Research Tecnology Management (Industrial Research Institute, Inc.), v. 45, no. 5, 13p., 2002. Disponível em: <http://www.stage-gate.com/pdfs/working\%20paper\%2014.pdf>. Acesso em: 10 jan. 2003.

DIMANCESCU, D.; DWENGER, K. O segredo do lançamento de produtos. HSM Management, no4, p.110-116, setembro de 1997.

GRIFFIN, A. PDMA research new product development practices: updating trends and benchmarking best practices. Journal of Product Innovation Management, New York, v.14, p.429-458, 1997.

GRIFFIN, A; PAGE, A. PDMA sucess measurement project: recommended measures for product development sucess and failure. Journal of Product Innovation Management, New York, v.13, p.478-496, 1996. 
GUNASEKARAN, A. An Integrated Product Development-Quality Management System for Manufacturing. The TQM Magazine, Vol. 10, No. 2, pp. 115-123, 1998.

NASCIMENTO, P.T.S.; MARX H. O sistema de inovação da Natura. In: SEMINÁRIOS EM ADMINISTRAÇÃO, 5., 2001, São Paulo. Anais... São Paulo: USP, 2001. Disponível em: <http://www.ead.fea.usp.br/Semead/Vsemead/Operações.htm>. Acesso em: 5 jul. 2002.

OHFUJI, T.; ONO M.; AKAO, Y. Métodos de desdobramento da qualidade (1). Belo Horizonte: Fundação Christiano Ottoni, 1997. 254p.

PETERS, A.J., ROONEY, E.M., ROGERSON, J.H., MCQUATER, R.E., SPRING, M. and DALE, B.G. New Product Design and Development: A Generic Model. The TQM Magazine, Vol. 11, No. 3, pp. 172-179, 1999.

PHILLIPS, R. et al. A Comparative Study of Six Stage-gate Approaches to Product Development. Integrated Manufacturing Systems, Vol. 10, No. 5, pp. 289-297, 1999.

POLIGNANO, L.A.C.; DRUMOND F.B. O papel da pesquisa de mercado durante o desenvolvimento de produtos. In: CONGRESSO BRASILEIRO DE GESTÃO DE DESENVOLVIMENTO DE PRODUTO, 3., 2001, Florianópolis. Anais... Florianópolis, 2001. 1CD.

RAHMAN, S. Product Development Stages and Associated Quality Management Approaches. The TQM Magazine, Vol. 7, No. 6, pp. 25-30, 1995.

ROZENFELD, H. et al. Gestão de Desenvolvimento de Produtos: Uma Referência a Melhoria do Processo. Saraiva, São Paulo, 2006.

SARANTOPOULOS, I.A. et al. Processo de transferência de tecnologia guiado pelo QFD. In: CONGRESSO BRASILEIRO DE GESTÃO DE DESENVOLVIMENTO DE PRODUTO, 1.,1999, Belo Horizonte. Anais... Belo Horizonte, 1994. p.15-24.

SHIBA, S.; G, A.; WALDEN, D. TQM - Quatro revoluções na gestão da qualidade. Porto Alegre: Artes Médicas, 1997. 409p.

VALERI, S.G. et al. Análise da implementação de um gate system em uma indústria fornecedora de setor automotivo. In: CONGRESSO BRASILEIRO DE GESTÃO DE DESENVOLVIMENTO DE PRODUTO, 2., 2000, São Carlos. Anais...São Carlos, 2000. $1 \mathrm{CD}$.

YIN R.K. Estudo de caso: planejamento e métodos. 2. ed. Porto Alegre: Bookman, 2001. 199p. 